\title{
Titrimetric Determination of Ascorbic Acid Levels in Some Citrus Fruits of Kurgwi, Plateau State Nigeria
}

\author{
J. G. Nangbes ${ }^{1 *}$, D. T. Lawam ${ }^{2}$, J. B. Nvau ${ }^{1}$, N. A. Zukdimma ${ }^{1}$ and \\ N. N. Dawam ${ }^{3}$ \\ ${ }^{I}$ Department of Chemistry, Plateau State University, Bokkos, PMB 2012, Jos. \\ ${ }^{2}$ Department of Chemistry, Collage of Arts Science and Technology, Kurgwi, Plateau State. \\ ${ }^{3}$ Department of Microbiology, Plateau State University, Bokkos, PMB 2012, Jos. \\ *Correspondence: E-mail: nangbesjg@gmail.com; nangbesj@yahoo.com
}

\begin{abstract}
Citrus samples of three different fruits, sweet orange (Citrus sinensis) lime (Citrus aurantifolia) and lemon (Citrus lemon) were picked fresh from the trees at intervals of seven days, from September to November at different locations in Kurgwi, washed and kept in the refrigerator at $4^{\circ} C$ pending analysis. Two stages of fruit development, Ripe and Unripe, were considered during sampling. The bark of these fruits were peeled off with sterile knife and sliced into half, then manually compressed into a $250 \mathrm{~cm}^{3}$ beaker and filtered off with glass wool in to a $100 \mathrm{~cm}^{3}$ beaker to remove the pulps which could block pipette jets. The Standard Methods of the Association of Official Analytical Chemists, AOAC methods, 939.13 and 966.18 were used for the determination of ascorbic acid in the fruit juice. Results of these determinations showed that sweet orange (Citrus sinensis) lemon (Citrus lemon) and lime (Citrus aurantifolia) have concentration range of $50.23 \mathrm{mg} / 100 \mathrm{~mL}-56$. $26 \mathrm{mg} / 100 \mathrm{~mL}, 51.33 \mathrm{mg} / 100 \mathrm{~mL}-53.47 \mathrm{mg} / 100 \mathrm{~mL}$ and $34.12 \mathrm{mg} / 100 \mathrm{~mL}-35.62 \mathrm{mg} / 100 \mathrm{~mL}$, respectively. The unripe species of all the fruits tend to have higher ascorbic acid content as shown in the results obtained, with sweet orange and lemon having almost twice the level of ascorbic acid than lime. Patients with diabetes, stroke, heart diseases and cancer etc could take more of sweet orange and lemon, which have higher levels of ascorbic acid than lime as revealed by this research.
\end{abstract}

Keywords: Ascorbic acid, Lemon, Lime, Sweet Orange.

\section{Introduction}

Ascorbic acid also known as vitamin $\mathrm{C}$ is the most important vitamin for human nutrition that is supplied by fruits and vegetables. It is a valuable nutritional component because of its antioxidant and therapeutic properties. It helps the body in forming connective tissues, bones, teeth, blood vessels and plays a major role as an antioxidant that forms part of the body defense system against reactive oxygen species and free radicals, thereby preventing tissue damage. ${ }^{[1,2,3]}$

Ascorbic acid is widely distributed in plant cells, which plays many crucial roles in growth and metabolism. It is also a potential antioxidant having the capacity to eliminate several different oxygen species keeping the membrane-bound antioxidant, $\alpha$-tocopherol (vitamin E) in the reduced state and so acts as a cofactor to maintain the activities of a number of enzymes by keeping metal ions in the reduced state which appears to be the substrate for oxalate and tartrate biosynthesis ${ }^{[4,5,6]}$.

It is widely used in the treatment of certain diseases such as scurvy, common cold, hemorrhagic disorder, wound healings as well as infertility. ${ }^{[7]}$ Ascorbic acid is also reported to be an important ingredient for the synthesis of dopamine, noradrenaline and adrenaline in the nervous system or in the adrenaline glands ${ }^{.8]}$

Ascorbic acid is also reported to be an essential antioxidant that helps protect against cancers, heart disease and stress. It is also part of cellular chemistry that provides energy, it is essential for sperm production and for making the collagen protein involved in the building and health of cartilage, joints, skin and blood vessels. Ascorbic acid helps in maintaining a healthy immune system, it aids in neutralizing pollutants, is needed for antibody production, acts to increase the absorption of nutrients (including iron) in guts, and thins the blood. [9]

Citrus fruits such as lime, lemon, orange, grape fruit and tomato are common sources of vitamin $\mathrm{C}$ or ascorbic acid. Other sources include papaya, broccoli, Brussels, sprouts, black berries, cauliflower, spinach, cantaloupe and blue berries.

Most plants and animals have the ability to synthesize ascorbic acid for their needs. The only mammals that are unable to synthesize ascorbic acids are primates including man and guinea pigs. Therefore, humans depend on exogenous sources of ascorbic acid which include fruits and vegetables as well as food supplements and pharmaceutical preparations. ${ }^{[3]}$ 
Lack of ascorbic acid in daily diet leads to a disease called scurvy, a form of vitaminosis that is characterized by loose teeth, superficial bleeding, fragility of blood vessels, poor healing, compromised immunity, mild anemia. The dietary amounts recommended by various authorities are $50-150 \mathrm{mg}$ of ascorbic acid per day. High doses (thousands of mg) are used but may result in diarrhea. Any excess of ascorbic acid is needed in the diet to prevent scurvy. It also has a reputation for being useful in the treatment of colds and flu. The evidence to support this idea however is ambiguous. ${ }^{[9]}$

The most important and prominent source of ascorbic acid or vitamin $\mathrm{C}$ is the plants and particularly, citrus fruits. Dominant citrus fruits in this part of the world are: sweet orange (Citrus sinensis) lime (Citrus aurantifolia) and lemon (Citrus lemon). These citrus species are abundant and mostly consumed by the people of the community (Kurgwi) to serve as their source of vitamin C. However, the availability of these fruits depends on their sources and storage time, which could also affect the levels of concentration of vitamin $\mathrm{C}$ in these fruits. It has been reported that the amount of vitamin $\mathrm{C}$ in fruits depends on the precise variety, the soil and climate in which it grew and the length of time it was picked. ${ }^{[8]}$

The human body cannot synthesize ascorbic acid by itself, and so has to get its source of the essential nutrient from its diet. In this research work, the levels of ascorbic acid in the three available citrus fruits were determine at two phases of fruit development, ripped and unriped. The aim of this work is to determine the levels of ascorbic acid concentration in the citrus species selected and also determine the phase of fruit development containing high concentration of ascorbic acid. This is with the aim of giving a guide as to the phase at which ascorbic acid levels are high in these fruits so as to enhance maximum benefits of the fruits in terms of vitamin $\mathrm{C}$ or ascorbic acid yield. This is because most people and industries prefer to take or use these fruits at their ripped stage.

\section{Sample collection and preparation}

\section{Materials and Methods}

Samples were picked fresh from the trees at intervals of seven days, from September to November at different locations, washed and kept in the refrigerator at $4^{\circ} \mathrm{c}$ pending analysis.

The bark of the fruits were peeled off with sterile knife and sliced into half, this was manually compressed into a $250 \mathrm{~cm}^{3}$ beaker and filtered off with glass wool in to a $100 \mathrm{~cm}^{3}$ beaker to remove the pulps which could block pipette jets.

\section{Methods}

Method used for the determination of ascorbic acid in the fruit juice was as specified in the standard AOAC methods, 939.13 and $966.18^{[10]}$

This method was chosen due to its advantages compared to other methods. It is sensitive, economic, practical and less time consuming. ${ }^{[8]}$

\section{Results and Discussion}

The average concentration of ascorbic acid as contained in the sample for the period of this work were as given in table 1 below.

Table 1: Average Ascorbic Acid Concentration in Fruit Species

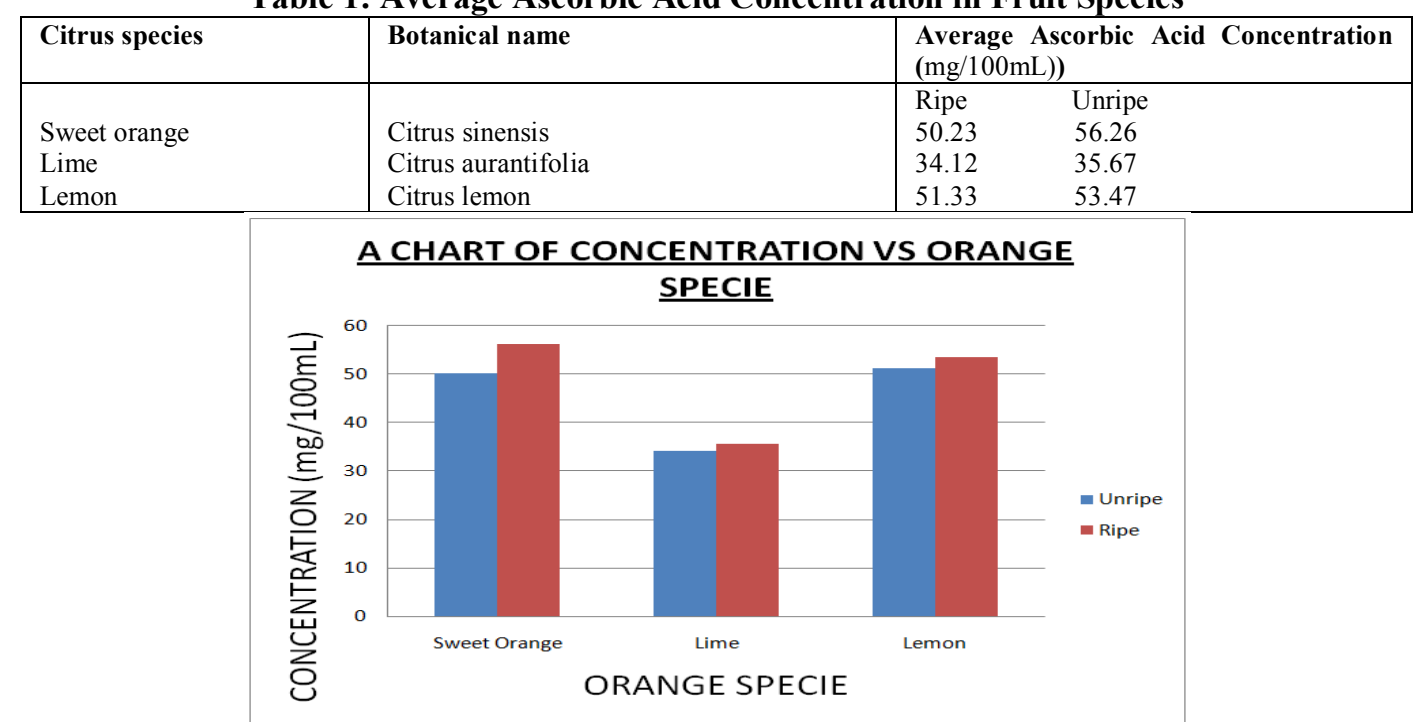

Fig. 1: A Chart of Ascorbic Acid Concentration versus Orange Species 
From the results, the unripe fruit samples have higher levels of ascorbic acid content than the ripe fruit samples. This may be attributed to the fact that in the process of repining, the fruits tend to absorb the ascorbic acid. $^{[9]}$

Also ascorbic acid content in sweet orange and lemon are comparatively similar $(50.23 \mathrm{mg} / 100 \mathrm{~mL}-56$. $26 \mathrm{mg} / 100 \mathrm{~mL}$ and $51.33 \mathrm{mg} / 100 \mathrm{~mL}-53.47 \mathrm{mg} / 100 \mathrm{~mL}$ respectively), but much lower in lime $(34.12 \mathrm{mg} / 100 \mathrm{~mL}$ $-35.62 \mathrm{mg} / 100 \mathrm{~mL})$.

These results show some difference with that reported by other works, were orange, lemon and lime have ascorbic acid levels of $64.0 \mathrm{mg} / 100 \mathrm{~mL}, 49.0 \mathrm{mg} / 100 \mathrm{~mL}$ and $56.56 \mathrm{mg} / 100 \mathrm{~mL}$ respectively. ${ }^{[11]}$

The difference between our results and those reported by other investigators for the fruit samples analyzed may be explained on the basis of the factors that affect ascorbic acid levels in fruits. These factors include; climate, temperature and amount of nitrogen fertilizers used in growing the plants. Climatic conditions such as light and temperature have been reported to affect the chemical composition of horticultural crops. It has been reported that fruits which are exposed to maximum sunlight have been shown to contain higher amount of ascorbic acid than those shaded on the same plant. ${ }^{[11]}$ Also it has been shown that grape fruits, also a species of citrus fruits grown in coastal areas of California generally contain more ascorbic acid than those grown in Desert areas of California and Arizona. ${ }^{[12]}$ This suggest that the lower level of ascorbic acid in our samples may also be due to the temperature weather from where the samples were picked.

However, results from this research work also agree with other reported works, were Valencia orange contain $43.42 \mathrm{mg} / 100 \mathrm{~mL}-52.30 \mathrm{mg} / 100 \mathrm{~mL}$ ascorbic acid levels ${ }^{[13,14]}$. This shows that temperate weather affects ascorbic acid concentration in citrus fruits.

\section{Conclusion}

The results of this research has revealed that unripe citrus fruits have higher levels of ascorbic acid than the ripe ones, with orange and lemon having almost twice the level of ascorbic acid than lime. This indicates that fruit industries that need to fortify their products with ascorbic acid or vitamin C would need more of unripe orange or lemon as the raw materials.

Also these results will provide a suitable guide to the population in the choice of fruits with high levels of ascorbic acid or vitamin $\mathrm{C}$ and also the level of fruit development that would maximize the harvest of vitamin $\mathrm{c}$ in the cause of consumption.

Patients with diabetes, stroke, heart diseases and cancer etc could take more of sweet orange and lemon, which have higher levels of ascorbic acid than lime as revealed by this research.

\section{References}

[1]. D.P Xu, M.P Wahburn, G.P Sun and W.W. Wells BiochemBiophys. Res commun, 221 (1996)117

[2]. A. Romay, J. Armesto, R Gonzalews, N. Ledon and I. GarciaInfamm. Res47 (1998) 36

[3]. M.T. Parriainen, in; A townsend (ed), encyclopedia of Analytical science vol. 9 Academic press, London (1995)

[4]. Arrigoni. O., De Tullio, M.C (2002). Ascorbic Acid: Much more than just an oxidant Biochemica et BiophysicaActa, 1569, 1-9

[5]. Davey M.W, Van Monyagu, M. Inze, D. Sanmartin, M. Kanellis, A, Sminoff, N. Benzie, I. J.J, Streain, J.J Favell D, Fletcher J. (2000). Plant L - ascorbic acid: chemistry, function, metabolism, bioavailability and effects of processing. Journal of the science of food and Agriculture, 80,825-860

[6]. Klein, B.P, \&Kurilich A.C (2000). Processing effects on dietary antioxidants from plant \& foods. Hortscience, 35 (4), $580-584$

[7]. Rasanu.etal. Analele University din Bucuresti - chimie, Anul xiv (serienouâ), vol 1 - 11, pg $167-172$

[8]. T.K. Basu and J. W.T.Dikerson, vitamins in Human Health and Disease cab International, Oxford, UK, PP 125 - 147. (1996)

[9]. Jing Yang, Katsuaki, Kato, Kenji Noguchi etal, (2003). life sciences, 73, 3245 - 56

[10]. AOAC (1999) Official methods of analysis of the Association of official Analytical chemist. $16^{\text {th }}$ edition, $5^{\text {th }}$ revision. AOAC international, Gaithersburg, M.D. method 939.13 \& 966.18

[11]. Okiei W. Ogunlesi M.Azeez,L. Obakachi, V. Osunsanmi, M. Nkenchor, G. (2009). The Voltametric and Titrimetric Determination of Ascorbic Acid levels in Tropical Fruit Samples. International Journal of Electrochemical Science. 4276 - 287

[12]. Lee S.K. and Kader A.A. (2000) post Harvest Biology and technology 20 pp 207

[13]. Masamba K.G. and Nguyen M. (2008). Determination and Comparison of Vitamin c, calcium and potassium in four selected conventionally and organically grown fruits and vegetables. African Journal of Biotechnology vol. 7 (16) pp $2915-2919$.

[14]. Al-Ani M, opera L.U, Al-Bahri D. and Al-Rahbi N. (2007). Journal of Food, Agriculture \& Environment vol. 5 (3\&4): 165 - 168 